\title{
FLUXO DE CAIXA E CONTROLES FINANCEIROS APLICADOS ÀS MICROEMPRESAS
}

\section{CASH FLOW AND FINANCIAL CONTROLS APPLIED TO MICRO-COMPANIES}

\author{
Jefferson Manosso de Castro \\ ORCID: http://orcid.org/0000-0001-7939-787X \\ Alessandro Lepchak \\ ORCID: http://orcid.org/0000-0003-0533-0386 \\ Flávio Ribeiro \\ ORCID: http://orcid.org/0000-0002-3547-9539 \\ Willson Gerigk \\ ORCID: https://orcid.org/0000-0003-2144-3452
}

\section{Resumo}

Este relato é originário de uma ação extensionista que teve como objetivo prover microempresas com informações relacionadas à administração financeira, por meio da utilização de controles de fluxo de caixa e sua avaliação. Trata-se de projeto isolado de extensão (7943/2017) que contou com a participação de três professores coordenadores e dez acadêmicos do curso de Ciências Contábeis da Unicentro-PR, campus de Irati. A seleção de empresas foi realizada no início de 2018. Ao final dessa etapa, o projeto contou com cinco empresas. O desenvolvimento ocorreu de abril/2018 até março/2019, via estudos multi casos. Após essa data, os relatórios construídos foram analisados e finalizados e as empresas receberam feedback sobre a proposta desenvolvida. Os relatórios fornecidos podem auxiliar a estruturar um planejamento financeiro e orçamentário nas organizações. O projeto constituiu-se em um adequado instrumento para unir a prática financeira desenvolvida pelas microempresas com a teoria vivenciada pelos acadêmicos em sala de aula.

Palavras-chave: Planejamento financeiro; Fluxo de caixa; Microempresas; Extensão.

Data recebimento: 07/05/2020

Data de aceite: 01/10/2020

\begin{abstract}
This report refers to an outreach action aimed to provide microbusinesses information about financial management through the use of cash flow control and its evaluation. The report refers to a specific outreach project (7943/2017) involving the participation of three coordinating professors and ten undergraduate students from the Accounting Science course at Unicentro-PR, Irati campus. The businesses were selected in early 2018 and at the end of this stage five businesses were involved in the project. The project was carried out from April/2018 to March/2019 through multiple case studies. After the analysis and conclusion of the reports the microbusinesses received feedback about the proposal. The study demonstrated that the reports may help structure the financial and budgetary planning of the organizations. It was also observed that the project was an appropriate instrument to articulate the financial practice developed by microbusinesses and the theory studied by the undergraduate students.
\end{abstract}

Keywords: Financial planning; Cash flow; Microbusinesses; Outreach project. 


\section{Introdução}

No Estado do Paraná, segundo o Sebrae (2016), 25,5\% das empresas constituídas em 2012 não completaram três anos de sobrevivência. Observa-se que houve evolução em relação às taxas das empresas constituídas em 2008, das quais apenas 58\% superaram os três primeiros anos de existência. Todavia, o dado exposto é preocupante, pois o período de análise contemplou um cenário economicamente favorável e ainda a massificação da constituição de negócios, sob a modalidade de microempreendedores individuais, impulsionou o percentual de sobrevivência.

Estudos realizados sobre a mortalidade das empresas indicam que os principais motivos para a inviabilização financeira se concentram em problemas conjunturais atrelados à questão burocrática, ao difícil acesso a políticas de financiamento (PANDOLFO; VELOSO, 2000) e também à falta de experiência e conhecimento relacionados à gestão dos negócios (COUTEN, 2018). Alvarenga (2016) cita que a falta de experiência em gestão empresarial, baixo nível de escolaridade, restrição de acesso ao crédito, pouca inovação e falta de planejamento estratégico são itens que influenciam diretamente o encerramento das atividades das microempresas, sendo que o estudo se concentrou em empresas do estado do Maranhão. Nota-se pelos resultados expostos que a qualificação e o conhecimento de técnicas e instrumentos gerenciais podem contribuir para a continuidade das organizações, reduzindo assim a possibilidade de falência.

A administração de uma empresa de sucesso exige a abordagem de vários pontos críticos no negócio, o mais sensível certamente é o setor de finanças. Sem capital disponível em curto ou longo prazo, a empresa não tem como honrar seus compromissos diários ou tão pouco financiar seu próprio crescimento. Não há empresa que se mantenha de portas abertas sem capital para pagar seus fornecedores, impostos, funcionários, etc. O planejamento financeiro, alinhado com as metas e estratégias da empresa, auxilia os gestores nas tomadas de decisões, contribuindo para o alcance de seus objetivos operacionais, econômicos e financeiros. Nas microempresas, o controle por meio da gestão financeira é fundamental para a sobrevivência, num cenário de frequentes e significativas mudanças na economia (CASALI; TRETER, 2015).

Segundo Formenti e Martins (2015), diante do cenário econômico cada vez mais globalizado e competitivo, administrar e garantir que a liquidez dos recursos em caixa seja suficiente para honrar com os compromissos assumidos pelas empresas é fundamental para sua continuidade.

Para Toledo Filho, Oliveira e Spessatto (2010), com relação à utilização do fluxo de caixa, os microempresários evidenciam que conhecem tal prática gerencial, porém há um grande número de administradores e empreendedores que não têm tal instrumento implantado nas organizações, desconhecendo o processo de administração e manutenção dos recursos financeiros. Pivetta (2004) relata, de forma prática, um modelo a ser utilizado por microempresas, sendo que o controle financeiro pode ser totalmente exequível em planilhas eletrônicas. Apesar da aplicação ser realizada de modo acessível a todas as empresas, os resultados gerados impactam diretamente na qualidade da tomada de decisão por parte dos gestores.

Strobel (2014) afirma que o planejamento do fluxo de caixa é um componente importante para o sucesso e continuidade dos negócios. A autora apresenta em seu trabalho a importância do fluxo de caixa em pequenas empresas familiares e comenta sobre a necessidade desses controles para o bem-estar de todos os envolvidos na organização. Visto que a 
correta gestão do caixa evita a falta de recursos financeiros para honrar as obrigações da empresa, bem como a utilização de recursos onerosos para essa finalidade.

Este relato foi gerado a partir de uma proposta extensionista criada em 2017, com dois anos de duração, sob a modalidade de projeto isolado de extensão (ação de extensão), sob o número de protocolo 7943/2017, e inclui três professores e dez alunos do curso de Ciências Contábeis, da Universidade Estadual do Centro-Oeste - Unicentro-PR, campus de Irati.

A ação visa responder à seguinte questão: Como a utilização de controles relacionados ao fluxo de caixa e sua avaliação pode auxiliar as microempresas em seu planejamento financeiro?

O objetivo geral consistiu em prover as microempresas participantes do projeto com informações relacionadas à administração financeira, por meio da utilização de controles pertinentes ao fluxo de caixa e sua avaliação. Não faz parte do escopo principal desse projeto a avaliação útil das informações produzidas e sim uma primeira fase de implantação para que as microempresas conheçam e se familiarizem com um importante instrumento para a administração financeira dos negócios e possam, futuramente, fazer o correto uso dessas informações para fins de planejamento e orçamento financeiro.

Os controles financeiros foram implantados em 05 microempresas da cidade de IratiPR e o acompanhamento e as análises dessas informações foram desenvolvidas por acadêmicos do curso de Ciências Contábeis da Unicentro-PR, campus de Irati, e envolveram informações financeiras para tomada de decisão e planejamento financeiro.

A justificativa social do projeto de extensão contempla os índices de mortalidade das empresas ora mencionados, de modo que o fluxo de caixa representa um auxílio à viabilidade de sobrevivência das empresas. Para Sá $(2008$; 2014), são inúmeros exemplos de empresas que se inviabilizaram financeiramente mesmo apresentando lucros contábeis. A análise do fluxo de caixa permite identificar, em tempo hábil, as causas e problemas na estrutura de capital de giro das empresas e proporcionar as devidas correções.

A relevância acadêmica do projeto situou-se em proporcionar aos acadêmicos participantes a possibilidade de vivenciarem situações reais e problemas cotidianos enfrentados pelas microempresas, bem com interligar os conhecimentos teóricos assimilados nas disciplinas do curso e aplicá-los em uma realidade organizacional, especificamente no que tange à situação financeira das organizações que participaram do projeto.

\section{Referencial Teórico}

\subsection{Gestão Financeira para microempresas}

As microempresas representam, segundo Henrique (2008), a maioria dos negócios em funcionamento e por isso são de fundamental importância para a economia do país, sendo 
grandes geradoras de empregos e riquezas, o que contribui de maneira significativa para aumentar o Produto Interno Bruto (PIB) do país.

Essas empresas vivem com aumento gradativo na concorrência de mercado e com constantes mudanças. Laurentino et al. (2008) ressalta que muitas das microempresas não estão estruturadas para enfrentar tal desafio. Dessa forma, a gestão financeira é um dos principais pontos de partida para o desenvolvimento das funções gerenciais no processo de tomada de decisão.

Para Couten (2018), a gestão incorreta de microempresas é uma das principais causas da sua mortalidade precoce, pois na maioria das vezes os gestores dessas organizações estão iniciando em suas atividades e carecem de experiência e conhecimentos para o desenvolvimento do negócio.

Do ponto de vista dos gestores, uma empresa pode ser visualizada como um sistema que gera lucro e aumenta os recursos nela investidos. A empresa é um conjunto de contratos, considerada um sistema aberto e dinâmico, representada por seus administradores e empregados, que interagem com os agentes econômicos do ambiente em que está inserida, gerando resultados que remunere os investimentos realizados (SUNDER, 2014).

Para Lima e Souza (2013), o mercado está mais exigente e competitivo e a contabilidade, como motivadora da informação, vem sendo inevitável para as organizações modernas, pois, por meio da aplicação de instrumentos contábeis gerenciais, o processo de desenvolvimento de estratégias de trabalho é facilitado, auxiliando os gestores no processo de tomada de decisão e gerando a maximização dos lucros. Todavia, Olyntho, Ribeiro e Munhão (2013) destacam que poucos empresários utilizam mecanismos de gestão financeira devido à falta de conhecimento.

No processo de geração de resultados, a medida mais comumente utilizada é o lucro líquido, sendo este uma boa indicação da capacidade de pagamento. Entretanto, a informação constante no fluxo de caixa ajuda a empresa a atingir seus objetivos, permitindo predições melhores das probabilidades futuras, servindo também para avaliação sobre a liquidez e solvência da organização (HENDRIKSEN; VAN BREDA, 2015).

$\mathrm{Na}$ gestão financeira, o objetivo econômico das empresas é a maximização dos resultados, o que aumentará a riqueza de seus proprietários. A geração permanente de caixa contribui para que uma empresa, no cenário contemporâneo, cumpra suas funções sociais por meio da distribuição de valor adicionado e ainda remunere os investidores de capital de forma satisfatória (HOJI, 2014).

Os proprietários esperam que seu investimento, na empresa, produza um retorno compatível com o risco assumido e com o capital investido. A administração financeira ocupase de tais questões, utilizando-se de técnicas e análises capazes de assegurar a longevidade dos negócios, diante do correto uso das disponibilidades financeiras das empresas.

Dentre as técnicas constantes na gestão financeira, o fluxo de caixa apresenta-se como uma ferramenta imprescindível para a gestão financeira e, consequentemente, ao processo decisório das empresas. Por meio do fluxo de caixa, o gestor pode programar e acompanhar 
as entradas e saídas de recursos financeiros, prevendo situações de modo a otimizar as informações financeiras da organização (ROSA; SILVA, 2002).

A necessidade de se desenvolver controles relacionados ao fluxo de caixa decorre do aumento da complexidade das atividades organizacionais, que provoca grandes disparidades entre o período no qual lançamentos de receitas e despesas são apresentados e o período em que os correspondentes fluxos de caixa realmente ocorrem. Essas disparidades emergem, principalmente, em razão dos recebimentos e pagamentos a prazo (HENDRIKSEN; VAN BREDA, 2015).

A precisão dos controles relacionados ao fluxo de caixa desempenha um papel fundamental no planejamento organizacional, uma vez que a liquidez e a gestão do risco da empresa são baseadas em dados financeiros robustos. Logo, todos os planos financeiros de uma organização derivam de um fluxo de caixa consistente e fidedigno (BLANC; SETZER, 2014).

Para Gitman (1997), o fluxo de caixa é a espinha dorsal da empresa. Sem ele não se saberá quando haverá recursos suficientes para sustentar as operações ou quando haverá necessidade de financiamentos bancários. Empresas que necessitem continuamente de empréstimos de última hora poderão se deparar com dificuldades em encontrar instituições que as financiem.

O controle sobre o caixa (recursos financeiros) é vital para o bom funcionamento de qualquer empresa. O modo como o fluxo de caixa é administrado pode determinar o sucesso ou o fracasso de uma empresa. Em uma organização, o que se espera é que as contas sejam pagas em seu vencimento e que o dinheiro excedente seja aplicado na compra de estoque, equipamentos ou na geração de rendimentos financeiros (CARDOSO et al., 2011).

Cavalcanti e Lourenço (2014) investigaram os elementos de controle presentes em microempresas. Os autores constataram que o fluxo de caixa é um instrumento amplamente utilizado pelas empresas, permitindo compreender o processo de liquidez da organização, pois identifica as atividades que estão contribuindo ou reduzindo os recursos financeiros, ou seja, as disponibilidades de caixa. A análise das entradas e saídas de recursos financeiros permite a estruturação desse fluxo em relatórios padronizados, segregando as atividades que compõem o caixa em três fontes principais: atividades operacionais (relacionadas à atividade principal da empresa), atividades de investimento (operações de compra e venda de ativos de longo prazo) e atividades de financiamento (captação de recursos em instituições financeiras ou junto aos proprietários) (SÁ, 2008).

\subsection{Atividades empresariais}

As atividades empresariais são classificadas de forma diferente em relação ao fluxo de caixa. Conforme sua natureza, podem relacionar-se com atividades operacionais, de investimentos ou de financiamentos.

As atividades operacionais existem em função do negócio da empresa e são executadas com a finalidade de proporcionar um retorno adequado para os investimentos feitos pelos proprietários (HOJI, 2014). Consistem no reconhecimento das entradas e saídas de recursos atrelados exclusivamente à(s) atividade(s) principal(is) da organização, ou seja, 
de sua operação, principalmente recebimentos de vendas à vista ou a prazo (recebimento de duplicatas), contrapondo-se aos pagamentos relativos à compra de mercadorias para revenda, de matérias-primas, despesas com mão de obra, despesas com vendas, administrativas e outras (CARDOSO et al., 2011).

Hoji (2014) ressalta que as atividades operacionais se relacionam, basicamente, com a compra e venda de mercadorias, compra de matéria-prima e sua transformação, venda de produtos, prestação de serviços, armazenagem e distribuição. As atividades auxiliares, que dão suporte ao negócio da empresa, tais como: planejamento, serviços jurídicos, publicidade, controles financeiros, dentre outros, também são consideradas como atividades operacionais, sendo classificadas como despesas.

Para o CPC (2010), o montante dos fluxos de caixa advindos das atividades operacionais é um indicador chave da extensão pela qual as operações da entidade demonstram sua capacidade de gerar caixa, ou seja, recursos financeiros, os quais são aplicados na manutenção da capacidade operacional da entidade, pagar suas dívidas, remunerar os proprietários (dividendos) e fazer novos investimentos sem precisar recorrer a fontes externas de financiamento. As informações históricas sobre os componentes dos fluxos de caixa operacionais são úteis, em conjunto com outras informações, para a projeção de fluxos futuros de caixa.

As atividades de investimento, nas empresas, são importantes pois representam as saídas de recursos feitos pela entidade com a finalidade de gerar lucros e fluxos de caixa no futuro. Somente desembolsos que resultam em ativo reconhecido nas demonstrações contabeis são passíveis de classificação como atividades de investimento (CPC, 2010).

São classificadas como investimentos as aplicações de recursos em caráter temporário ou permanente, que servem para dar suporte às atividades operacionais, como por exemplo, desembolsos com a aquisição de um imóvel, de equipamentos, de máquinas, de participações acionárias em outras empresas, entre outros; e os recebimentos decorrentes de vendas desses mesmos ativos (CARDOSO et al., 2011; HOJI, 2014).

As atividades de financiamento refletem os efeitos das decisões tomadas sob a forma de financiamento das atividades operacionais e de investimento. Correspondem, em especial, pela busca de recursos realizada pela empresa junto a outras instituições para suprir suas necessidades de caixa.

As atividades de financiamento são importantes por serem úteis na predição de exigências de fluxos futuros de caixa por parte de fornecedores de capital à entidade. Exemplos podem ser descritos como a captação de empréstimos bancários, emissão de debêntures, integralização de capital da empresa, pagamento de lucros e dividendos, dentre outros (CPC, 2010).

\section{Metodologia}

O projeto foi desenvolvido por meio de estudo de multi casos, pois contempla em seu escopo 5 microempresas situadas na cidade de Irati-PR. Considera-se microempresa a 
entidade cujo o faturamento anual não exceda $\mathrm{R} \$ 360.000,00$, de acordo com o inciso I do art. $3^{\circ}$ da Lei Complementar 123/2006 (BRASIL, 2006).

O estudo contempla análise descritiva e se faz valer de processo documental para coleta de informações. As informações tratadas são estritamente quantitativas e foram coletadas pessoalmente junto às organizações e também via e-mail. O contato inicial se deu com os gestores das organizações e, em um segundo momento, os funcionários envolvidos no processo financeiro também participaram no fornecimento das informações necessárias à construção do fluxo de caixa.

A duração do projeto foi de 24 meses, sendo desenvolvido no município de Irati-PR. $\mathrm{O}$ processo foi segregado em cinco etapas e as atividades foram desenvolvidas em conjunto por todos os participantes (professores e alunos), a saber:

i) desenvolvimento de material didático envolvendo conceitos, objetivos e finalidades do controle financeiro e os instrumentos utilizados nessa finalidade, a ser apresentado na etapa da sensibilização e seleção das empresas. Também foi apresentada a estrutura preliminar do instrumento de fluxo de caixa a ser aplicada nas etapas seguintes do projeto. Esta etapa foi desenvolvida em conjunto com os acadêmicos participantes e visou, além de estruturar as etapas do projeto, possibilitar aos discentes a aplicação dos conhecimentos teóricos adquiridos sobre controle financeiro, bem como o envolvimento no planejamento de atividades junto às empresas;

ii) sensibilização e seleção de empresas participantes do processo - desenvolveu-se por meio de reuniões e divulgação da proposta às empresas interessadas. Buscou-se, nesta etapa, selecionar as empresas e motivá-las à participação da ação extensionista;

iii) explicação e implantação de ferramentas relacionadas ao controle financeiro sob a forma de fluxo de caixa - esta etapa consistiu em fornecer subsídios teóricos, tecnológicos e intelectuais para que as empresas pudessem colocar em prática o instrumento gerencial de fluxo de caixa. Tal instrumento foi desenvolvido em planilha eletrônica (disponibilizada em formato de arquivo do Microsoft Excel ${ }^{\circledR}$ ) ou, em alguns casos, as empresas já desenvolviam ou possuíam tais controles. Desse modo, os controles foram coletados e analisados, não sendo necessária a fase de implantação;

iv) acompanhamento das informações e do correto desenvolvimento do fluxo de caixa - nessa etapa, acadêmicos e coordenadores do projeto fizeram o processo de conferência e revisão do preenchimento correto do fluxo de caixa. Distorções ou erros de preenchimento foram corrigidos para dar maior confiabilidade às informações coletadas;

v) avaliação das informações produzidas pela empresa com vistas à previsão e antecipação de cenários no que tange às atividades operacionais, de investimento e de financiamento das organizações - consiste na etapa final do projeto, na qual acadêmicos e coordenadores emitem às empresas pareceres acerca das informações coletadas.

Os resultados dos fluxos de caixa das empresas foram organizados em grupos, conforme a estrutura da Demonstração dos Fluxos de Caixa proposta pelo Comitê de Pronunciamentos Contábeis (CPC, 2010). As análises foram conduzidas de acordo com a 
análise de gestão do caixa baseada em autores da área contábil/financeira (ASSAF NETO, 2012; HOJI, 2014; MATARAZZO, 2003; SÁ, 2008). O feedback sobre os achados das análises foi fornecido individualmente a cada empresa por meio de relatório específico entregue ao gestor, via e-mail ou pessoalmente. Como as informações coletadas possuem sigilo empresarial, não são fornecidos detalhes minuciosos sobre as empresas participantes. Para identificá-las, foram atribuídos números e algumas de suas características explicitadas no tópico destinado aos resultados e discussões.

Os coordenadores do projeto extensionista são vinculados ao Departamento de Ciências Contábeis da Unicentro, campus de Irati - DECIC/I, e estimularam a participação de acadêmicos interessados em vivenciar o cotidiano financeiro das organizações a fim de propor a aplicação de conceitos adquiridos ao longo do curso de Ciências Contábeis. Assim o projeto contou ao todo com 10 acadêmicos durante os 24 meses de duração. As informações financeiras apresentadas neste artigo compreendem o período de abril a dezembro de 2018, porém as empresas forneceram informações para o projeto extensionista até o mês de abril de 2019.

\section{Resultados}

A primeira fase do projeto contemplou a preparação e produção de material a ser implantado posteriormente nas empresas. Nessa fase, os acadêmicos e professores construíram planilhas integradas que, se bem utilizadas pelas empresas, podem proporcionar importantes informações financeiras e operacionais.

A produção das planilhas envolve a capacidade de sintetização das informações financeiras e o processo correto de estruturação de dados dentro de uma lógica adequada contábil e financeira. Assim, foi considerado, além dos autores mencionados na metodologia, o cpc 03 (cpc, 2010) que contém as informações financeiras mais comuns no âmbito empresarial.

As planilhas foram desenvolvidas em Excel ${ }^{\circledR}$ e resultaram nos seguintes instrumentos:

I) Planilha de fluxo de caixa composta por seis guias divididas em: lançamentos, entradas, saídas, saldo do dia, saldo de contas e fluxo de caixa;

II) Planilha de contas a pagar;

III) Planilha de contas a receber;

IV) Planilha de controle de estoque.

A figura 1 ilustra a planilha relacionada ao lançamento de entradas e saídas de caixa. 
Figura 1 - Captura de tela da planilha eletrônica de controle de fluxo de caixa

\section{PLANILHA DE LANÇAMENTOS}

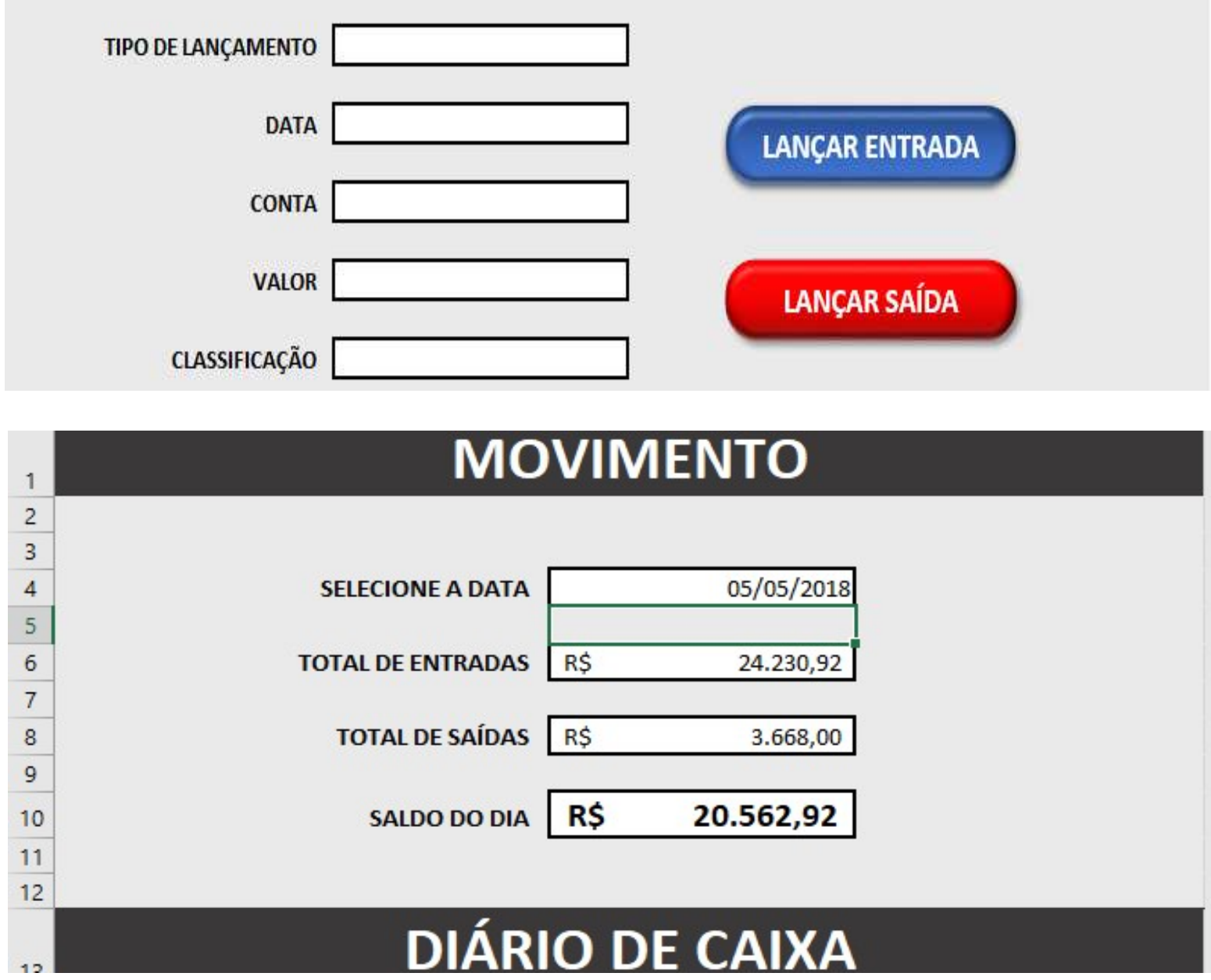

Fonte: Dados do projeto extensionista (2018)

Após efetivado o lançamento nos campos apresentados na Figura 1, os controles implantados geravam relatórios analíticos, no Excel $^{\circledR}$, usados para acompanhar os lançamentos diários do movimento financeiro das empresas, conforme apresentado na Figura 2.

Os valores apresentados na Figura 2, automaticamente, eram classificados por data para facilitar o acompanhamento dos lançamentos por parte da empresa. Tal processo justifica-se, pois facilita a conferência dos valores lançados, auxilia em uma possível auditoria dos valores e fatos financeiros e também separa as operações e contas financeiras que a empresa utiliza para o movimento financeiro. 
Figura 2 - Controle analítico de movimentação financeira

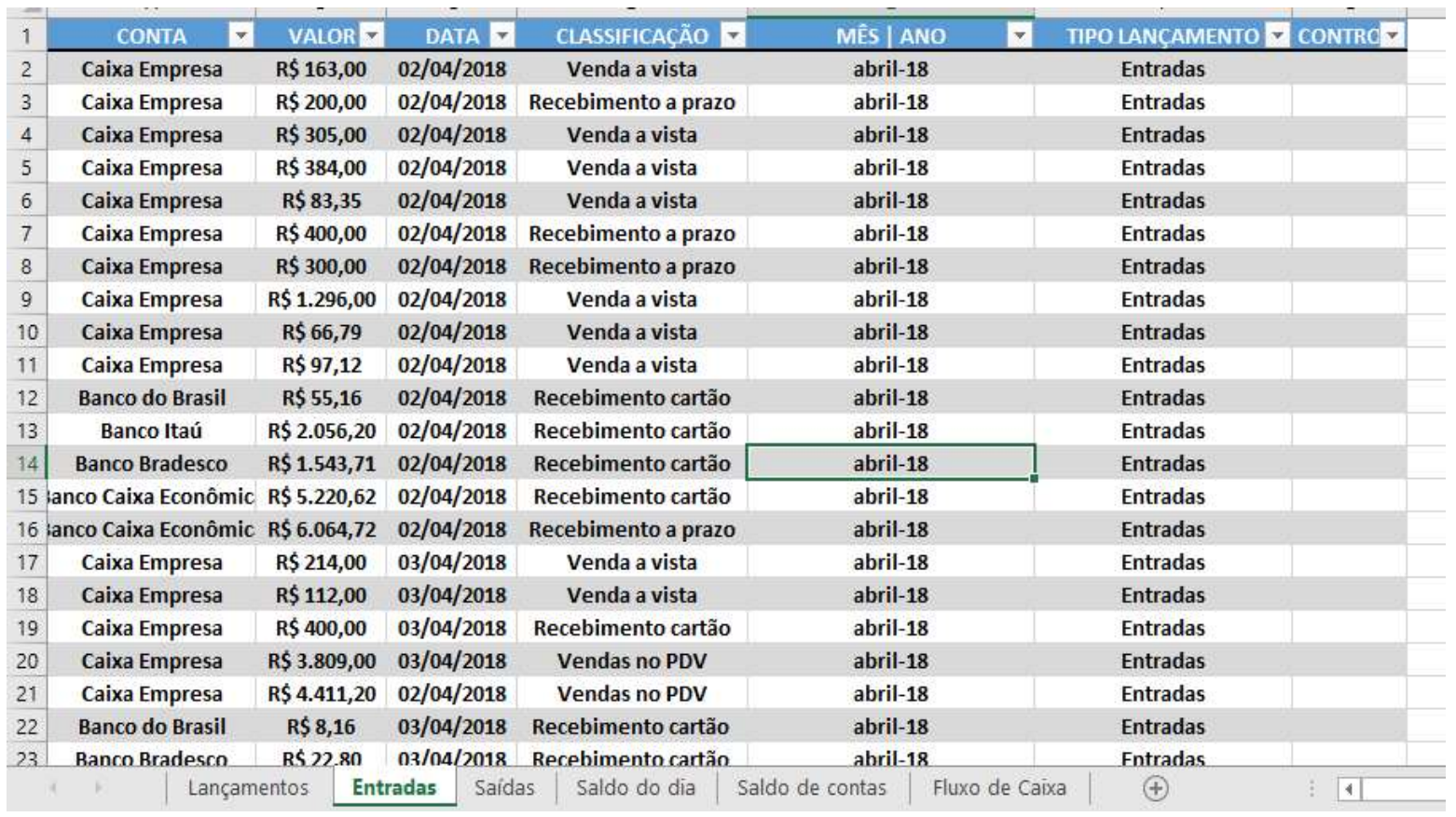

Fonte: Dados do projeto extensionista (2018)

Com as informações fornecidas de modo analítico (Figura 2), os acadêmicos e professores filtram os lançamentos, aglutinando fatos contábeis semelhantes (vendas à vista, recebimento a prazo, recebimento via cartão, etc.) a fim de gerar relatórios financeiros úteis para que as empresas tivessem subsídios eficientes para a tomada de decisão e acompanhamento da situação financeira das organizações.

A segunda fase foi a de prospecção de empresas aptas a participar do projeto e dispostas a fornecer seus dados financeiros para análise. Essa etapa contou com divulgação por meio da internet, visitas às empresas para divulgação e também junto à ACIAI (Associação Comercial e Empresarial de Irati). A seleção ocorreu por meio de visitas e reuniões durante o mês de março de 2018, sendo selecionadas cinco empresas, suas características constam do Quadro 1.

Percebe-se, pelas características, que há certa diversificação entre os participantes do projeto. Logo, a necessidade de controles financeiros efetivos não é demanda única e exclusivamente para empresas que estão em fase inicial ou de crescimento e atinge sim vários setores e portes diferentes de microempresas. 
Quadro 1 - Empresas participantes do projeto

\begin{tabular}{|c|c|}
\hline Empresas & Características \\
\hline $\begin{array}{l}\text { Empresa } 1 \\
\text { Mercado, Açougue }\end{array}$ & $\begin{array}{l}\text { - 50\% da atividade corresponde a açougue; - Clientes PF e PJ; } \\
\text { - Não possui controle de estoques efetivo; } \\
\text { - Empresa tem faturamento / receitas mas não apresenta saldos suficientes de caixa; } \\
\text { - Necessidade de controles inicial de caixa e contas a pagar e recebe; } \\
\text { - Possui também atividade de panificação; } \\
\text { - Administração familiar. }\end{array}$ \\
\hline $\begin{array}{l}\text { Empresa } 2 \\
\text { Farmácia }\end{array}$ & $\begin{array}{l}\text { - Participou do Programa Varejo Mais do Sebrae; } \\
\text { - Possui uma filial; } \\
\text { - Possui controle de caixa estruturado; } \\
\text { - Precisa de maiores informações para tomada de decisão; } \\
\text { - Estrutura DRE mensalmente; } \\
\text { - Interesse no indicador de Ponto de Equilíbrio, análise por linhas, prazos médios, etc. }\end{array}$ \\
\hline $\begin{array}{l}\text { Empresa } 3 \\
\text { Eletrônica }\end{array}$ & $\begin{array}{l}\text { - Política de compra à vista; } \\
\text { - Possui serviços integrados como pequenos reparos e montagem de alto-falantes; } \\
\text { - Empresa familiar, não há funcionários; } \\
\text { - Necessita de um controle de estoques e contas a pagar / receber; } \\
\text { - Controles estruturados em cadernos. }\end{array}$ \\
\hline $\begin{array}{l}\text { Empresa } 4 \\
\text { Mídia Digital }\end{array}$ & $\begin{array}{l}\text { - Estratégias digitais; } \\
\text { - Divulgação / publicidade; } \\
\text { - Empresa fundada em março de } 2018 ; \\
\text { - Maioria dos gastos são fixos; } \\
\text { - } 3 \text { sócios sem relações familiares; } \\
\text { - Principais clientes são empresas; } \\
\text { - Baixo investimento inicial; } \\
\text { - Diversifica a receita entre serviços fixos (valores mensais) e variáveis. }\end{array}$ \\
\hline $\begin{array}{l}\text { Empresa } 5 \\
\text { Serviços Gráficos }\end{array}$ & $\begin{array}{l}\text { - Administração familiar (casal); } \\
\text { - Clientes principais são PJ; } \\
\text { - Remanejamento de funcionários conforme demanda de serviço; } \\
\text { - A empresa controla apenas as ordens de produção; } \\
\text { - Não sabe posições de clientes em aberto e fornecedores; } \\
\text { - Alto investimento em máquinas que atualmente estão desvalorizadas; } \\
\text { - Empresa com mais de } 15 \text { anos de atuação no mercado. }\end{array}$ \\
\hline
\end{tabular}

Fonte: Dados do projeto (2019)

Apenas a empresa 4 está enquadrada, tributariamente, sob a forma de microempreendedor individual, sendo que as demais organizações fazem parte do regime tributário do Simples Nacional, sob a classificação de microempresa. Destaca-se, ainda, para todas as empresas, que a gestão direta cabe aos sócios e que não há muita delegação de funções financeiras para funcionários especializados. Apenas a empresa 2 possui e mantém um departamento financeiro com funcionário exclusivo para desempenhar tal função. 
As informações financeiras coletadas por meio das planilhas exibidas nas Figuras 1 e 2 ou por meio de outros controles que algumas empresas já possuíam, foram tratadas e organizadas conforme a estrututra da DFC constante no CPC 03 (CPC, 2010), ou seja, divididas em atividades operacionais, de financiamento e de investimento. Essa etapa é importante para que os acadêmicos tenham acesso à prática operacional que acontece nas empresas, de modo a perceber na prática como ocorrem certas operações financeiras exploradas em várias disciplinas do curso de Ciências Contábeis. Além da divisão das atividades, também é mostrado na Tabela 1 o resultado de caixa do período e o saldo de caixa mensal de cada empresa participante do projeto, relativo ao ano de 2018.

Tabela 1 - Informações financeiras das empresas no ano de 2018

\begin{tabular}{lrrrrrrrrrr}
\hline \multicolumn{1}{c}{ Empresa 1 } & Abr & \multicolumn{1}{c}{ Mai } & Jun & Jul & Ago & Set & Out & Nov & Dez & Total \\
\hline Operacionais & 4.665 & 11.142 & 9.230 & 9.358 & 9.967 & 10.203 & 9.172 & 9.248 & 10.089 & 83.075 \\
Financiamento & 8.829 & 8.690 & 8.627 & 8.799 & 8.776 & 8.773 & 8.770 & 8.778 & 8.771 & 78.813 \\
Investimento & 32 & 0 & 27 & 18 & 23 & 19 & 22 & 21 & 22 & 183 \\
Resultado & 4.196 & 2.452 & 576 & 541 & 1.169 & 1.411 & 380 & 449 & 1.296 & 4.078 \\
Saldo de Caixa & 6.744 & 4.291 & 3.715 & 3.174 & 2.005 & 594 & 215 & 234 & 1.530 & 1.530
\end{tabular}

\begin{tabular}{lrrrrrrrrrr}
\hline \multicolumn{1}{c}{ Empresa 2 } & Abr & Mai & Jun & Jul & Ago & Set & Out & Nov & Dez & Total \\
\hline Operacionais & 39.351 & 37.621 & 37.408 & 33.114 & 39.847 & 44.071 & 34.455 & 36.143 & 34.053 & 376.075 \\
Financiamento & 35.662 & 35.001 & 35.397 & 35.219 & 35.296 & 35.235 & 35.251 & 35.242 & 35.243 & 349.798 \\
Investimento & 2.788 & 2.824 & 2.812 & 1.500 & 3.250 & 2.400 & 800 & 4.000 & 3.500 & 27.320 \\
Resultado & 901 & 204 & 801 & 3.605 & 1.301 & 6.436 & 1.596 & 3.099 & 4.690 & 1.043 \\
Saldo de Caixa & 8.561 & 8.357 & 7.556 & 3.951 & 5.252 & 11.688 & 10.092 & 6.993 & 2.303 & 2.303 \\
\hline
\end{tabular}

\begin{tabular}{lrrrrrrrrrr}
\hline \multicolumn{1}{c}{ Empresa 3 } & Abr & Mai & \multicolumn{1}{l}{ Jun } & Jul & Ago & Set & Out & Nov & Dez & Total \\
\hline Operacionais & 3.558 & 2.863 & 2.454 & 5.112 & 5.603 & 4.090 & 5.358 & 5.726 & 6.135 & 40.897 \\
Financiamento & 3.572 & 3.020 & 2.695 & 3.507 & 5.363 & 4.161 & 5.168 & 5.461 & 5.786 & 38.734 \\
Investimento & 0 & 0 & 0 & 1.300 & 0 & 0 & 0 & 0 & 0 & 1.300 \\
Resultado & 14 & 157 & 241 & 305 & 240 & 71 & 189 & 265 & 349 & 864 \\
Saldo de Caixa & 576 & 419 & 178 & 482 & 722 & 651 & 840 & 1.105 & 1.454 & 1.454 \\
\hline
\end{tabular}




\begin{tabular}{llrrrrrrrrr}
\hline \multicolumn{1}{c}{ Empresa 4 } & Abr & \multicolumn{1}{l}{ Mai } & Jun & Jul & Ago & Set & Out & Nov & Dez & Total \\
\hline Operacionais & 4.468 & 1.229 & 2.770 & 4.830 & 3.399 & 5.171 & 1.570 & 5.157 & 4.942 & 33.539 \\
Financiamento & 2.500 & 2.000 & 3.000 & 3.000 & 3.000 & 4.000 & 4.000 & 4.000 & 4.000 & 24.500 \\
Investimento & 5.500 & 0 & 0 & 0 & 0 & 0 & 0 & 0 & 0 & 5.500 \\
Resultado & 1.468 & 771 & 230 & 1.830 & 399 & 1.171 & 2.430 & 1.157 & 942 & 3.539 \\
Saldo de Caixa & 1.468 & 698 & 468 & 2.298 & 2.698 & 3.869 & 1.439 & 2.596 & 3.539 & 3.539 \\
\hline
\end{tabular}

\begin{tabular}{lrrrrrrrrrr}
\hline \multicolumn{1}{c}{ Empresa 5 } & Abr & \multicolumn{1}{c}{ Mai } & Jun & \multicolumn{1}{c}{ Jul } & Ago & Set & Out & Nov & Dez & Total \\
\hline Operacionais & 2.659 & 14.630 & 3.704 & 23.060 & 8.565 & 9.192 & 19.996 & 11.315 & 14.796 & 84.215 \\
Financiamento & 421 & 5.458 & 5.494 & 5.597 & 5.463 & 5.519 & 5.529 & 5.705 & 5.656 & 44.841 \\
Investimento & 1.099 & 1.739 & 850 & 5.203 & 2.230 & 739 & 1.247 & 557 & 2.017 & 15.679 \\
Resultado & 4.179 & 7.434 & 2.640 & 12.261 & 871 & 15.449 & 13.220 & 5.053 & 7.123 & 23.695 \\
Saldo de Caixa & 1.401 & 8.835 & 6.196 & 18.457 & 19.328 & 3.879 & 17.099 & 22.152 & 29.275 & 29.275 \\
\hline
\end{tabular}

Fonte: Dados do projeto (2019). As três primeiras linhas de cada empresa (operacionais, financiamento e investimento) referemse aos fluxos de caixa da entidade separados conforme modelo institucionalizado pelo CPC 03. Logo, tem-se que as atividades operacionais são as principais geradoras de receita para a entidade, as atividades de investimento referem-se à aquisição de ativos de longo prazo e outros investimentos e as atividades de financiamento resultam em mudanças no tamanho e na composição do capital próprio e de terceiros da entidade. A linha de 'resultado' representa o resultado de caixa, ou seja, a soma dos três fluxos apresentados: operacionais, financiamento e investimento. Os valores destacados em vermelho são valores negativos. A linha 'saldo de caixa' refere-se à posição final de caixa no mês analisado. Apesar da razoabilidade das contas contábeis não permitir valores de caixa em negativo, a empresa 2, nos meses de Abril a Outubro apresentou valores negativos em virtude de contas bancárias negativas, assim, tais resultados foram mantidos por se tratar de uma análise financeira, sendo que, se o objeto de análise fosse o balanço patrimonial, tais contas devem ser apresentadas como obrigações de curto prazo da entidade. Os valores da empresa 1 estão indexados para preservar dados confidenciais da empresa, conforme solicitação da mesma.

A empresa 1 apresenta altos valores na atividade de Financiamento (captação de recursos externos) ocasionados por pagamentos de altas parcelas de empréstimos e juros. Esses valores comprometem consideravelmente o caixa da empresa, fato que resulta em conta corrente negativa em muitos meses. Apesar de apresentar melhora aparente de caixa no final do ano de 2018, a empresa continuou deficitária financeiramente nos primeiros meses do ano de 2019. O caixa gerado nas operações ou operacional (resultante da atividade principal da empresa) é quase que totalmente consumido pelos valores de financiamentos, não restando valores disponíveis para novos investimentos e nem para remuneração aos sócios. Em razão disso, a empresa tem retirada fixa para os sócios sendo que, por possuir valores negativos de caixa e ser um valor consideravelmente baixo em relação ao caixa operacional, foram lançados juntamente com as despesas administrativas da entidade. 
As demais empresas apresentaram cenários mais equilibrados. A empresa 4, apesar de ser uma organização recém criada, possui um cenário favorável por ter menor volume de contas a pagar e assim menor fluxo financeiro de informações a serem geridas. Como a gestão é realizada pelos sócios, tal atribuição acaba sendo facilitada por um volume de negócios de uma empresa que está iniciando suas atividades.

A partir dos fluxos de caixa, foram calculados alguns indicadores utilizando a Geração Bruta de Caixa, ou seja, a capacidade geral da empresa em gerar recursos financeiros, em relação aos principais pagamentos realizados, como o intuito de fornecer uma análise vertical do fluxo de caixa. Os pagamentos foram divididos pelo valor bruto da entrada de caixa (geração bruta de caixa), assim, é possível identificar quanto cada pagamento consome dos recursos financeiros conseguidos em termos percencetuais. O percentual resultante dessas razões é importante para dar entendimento à informação financeira calculada nos fluxos de caixa, fornecendo informação preditiva sobre os cenários que a empresa enfrenta. Tem-se, na Tabela 2, os cálculos dos referidos percentuais.

Tabela 2 - Indicadores baseados na gestão de caixa calculados para o ano de 2018

\begin{tabular}{|c|c|c|c|c|c|}
\hline INDICADORES & EMP 1 & EMP 2 & EMP 3 & EMP 4 & EMP 5 \\
\hline Saldo Final / Geração Bruta de Caixa & $0,45 \%$ & $0,29 \%$ & $0,49 \%$ & $4,73 \%$ & $6,39 \%$ \\
\hline Resultado Caixa / Geração Bruta de Caixa & $1,19 \%$ & $-0,09 \%$ & $0,72 \%$ & $4,73 \%$ & $5,17 \%$ \\
\hline Remuneração dos Sócios / Geração Bruta de Caixa & $0,88 \%$ & $18,31 \%$ & $23,15 \%$ & $40,08 \%$ & $7,46 \%$ \\
\hline Investimento / Geração Bruta de Caixa & $0,05 \%$ & $2,37 \%$ & $1,08 \%$ & $7,35 \%$ & $3,42 \%$ \\
\hline Caixa Operacional / Geração Bruta de Caixa & $24,30 \%$ & $32,66 \%$ & $34,03 \%$ & $44,81 \%$ & $18,37 \%$ \\
\hline Impostos / Geração Bruta de Caixa & $1,67 \%$ & $1,66 \%$ & $9,33 \%$ & $0,65 \%$ & $5,84 \%$ \\
\hline Empréstimos / Geração Bruta de Caixa & $18,68 \%$ & $9,86 \%$ & $6,27 \%$ & $0,00 \%$ & $2,10 \%$ \\
\hline
\end{tabular}

Fonte: Dados do Projeto (2019). Entende-se por Geração Bruta de Caixa as entradas líquidas de caixa originadas por atividades principais da empresa, ou seja, entrada de caixa proveniente de venda de produtos e serviços relacionadas ao negócio que a empresa executa, excluídas devoluções e abatimentos concedidos. Saldo Final corresponde ao saldo final do período analisado. Investimento é representado pelas saídas de recurso proveniente de valores lançados nas atividades de investimento na DFC. Remuneração dos sócios é qualquer remuneração paga pela empresa a seus sócios, podendo ser prólabore ou qualquer outro tipo de pagamento. Os valores de distribuição aos sócios foram mantidos nas tabelas de análise dentro do grupo das atividades de investimento.

A empresa 5, apesar de possuir um maior saldo final de caixa em comparação com os ingressos brutos de caixa, enfrenta problema recorrente de sazonalidade. Tal problema tem origem nos contratos com órgão públicos. Desse modo, a empresa não depende apenas da finalização de seus serviços, mas conta com a finalização do empenho por parte dos contratantes. Isso acarreta em alta variabilidade de resultado de caixa nas atividades operacionais. 
As empresas 4 e 5 conseguem investir maiores montantes em ativos fixos, percentuais de $7,35 \%$ e $3,42 \%$ respectivamente. A renovação ou investimento constante em ativos fixos (também chamados de ativo imobilizado) é necessário para que a empresa se mantenha competitiva e consiga proporcionar estrutura adequada para suprir as necessidades de atendimento à demanda de mercado e à tecnologia, aspectos que influenciam o aumento de participação no mercado. Apesar do indicador de $7,35 \%$ da empresa 4 , trata-se de um investimento inicial, pois a organização deu início às suas atividades no ano de 2018, para tanto, fez um aporte com capital próprio (investimento dos sócios).

Alta dependência de instituições financeiras (empréstimos/geração bruta de caixa), ou seja, alto endividamento é percebido na empresa 1, assim como notado na Tabela 1 que expõe os valores absolutos dos fluxos de caixa. Do total de entradas de caixa da empresa, 18,68\% (percentual anual) é destinado para honrar os empréstimos em seu valor absoluto. Se forem adicionados os juros a esses pagamentos, chega-se à $23,06 \%$ dos recursos financieros conseguidos que foram destinados ao pagamento de dívidas junto a terceiros, durante o ano de 2018. O cenário para a empresa 1 não é favorável, pois com todo esse desembolso para honrar suas obrigações com terceiros, não consegue investir em ativo fixo e muito menos remunerar os sócios pelo capital empregado na empresa. Uma reestruturação organizacional e financeira pode ser feita a partir do alerta encontrado nesta análise.

A maior remuneração para os sócios é percebida nas empresas 2, 3 e 4 . A empresa 2, apesar de possuir pagamentos de empréstimos, também possui alta margem de lucro e um departamento financeiro bem estruturado, fato este que certamente contribui para que a empresa destine $18,31 \%$ das entradas de caixa para os sócios. As empresas 3 e 4 trabalham com serviços que possuem maior valor agregado, desse modo, permitem aliar uma alta margem de lucro à baixa dependência de empréstimos. Sendo assim, os valores distribuídos aos sócios respondem, no ano de 2018, a 23,15\% e 40,08\% dos recursos financeiros conseguidos, respectivamente.

A remuneração dos sócios é um dos itens cruciais para o êxito financeiro das microempresas. Empresas que bem gerenciam a separação entre valores destinados às con-tas pessoais dos sócios e às contas da empresa (em uma linguagem contábil, isso é denominado princípio da entidade) aumentam suas expectativas futuras em virtude da compreensão, disciplina e correta mensuração dos resultados financeiros da organização. As empresas alvo deste estudo compreendem tal segregação, pois nos controles financeiros analisados destacaram corretamente os pagamentos relacionados aos sócios.

Percebe-se que controles financeiros estruturados auxiliam as empresas à percepção dos caminhos percorridos pelo dinheiro dentro da organização. Em microempresas, em que o controle e avaliação geralmente é feito pelo proprietário, esses resultados se acentuam de maneira considerável de modo a ilustrar o fluxo financeiro dentro das organizações e proporcionar uma maior compreensão dos resultados segregados nas atividades operacionais, de investimento e de financiamento. 


\section{Conclusão}

O presente relato apresentou alguns resultados provenientes de uma ação extensionista que teve como objetivo geral prover microempresas com informações relacionadas à administração financeira, por meio da utilização de controles relacionados ao fluxo de caixa e sua avaliação. O projeto foi desenvolvido em cinco empresas da cidade de Irati-PR e os resultados aqui apresentados referem-se ao ano de 2018.

Os resultados alcançados mostram que os controles financeiros permitem às empresas olhar em pontos estratégicos até então não explorados nos controles convencionais. Logo, a segregação em atividades operacionais, de financiamento e de investimento proporcionou o cálculo de alguns indicadores que podem ser alvo de análise da equipe gestora das organizações.

O trabalho mostrou às empresas que, além da compreensão e dinâmica dos processos envolvendo o fluxo de caixa, uma correta estruturação dos resultados financeiros pode ser o primeiro passo para implantações e melhorias do planejamento e na tomada de decisão. Os mecanismos sugeridos também podem servir de base para o delineamento dos planos estratégicos e orçamentários das empresas.

O projeto forneceu aos estudantes de Ciêncías Contábeis um processo de integração entre a teoria repassada durante o curso com a prática percebida nas organizações. Auxiliar as microempresas foi um aspecto interessante, pois trabalha itens necessários à profissão contábil como organização, senso crítico, visão holística, familiarização com banco de dados, dentre outros aspectos importantes à personalidade e atuação do contador.

A produção de material auxiliar para microempresas também é item resultante do projeto. Esse material pode ser acessado por qualquer pessoa por meio do link do dropbox, a saber: https://www.dropbox.com/sh/2u37r8ns7bvo49b/AACCj-1djSuBRSApmgCASHWwa?dl=0. As planilhas podem auxiliar outras microempresas a controlarem melhor suas finanças e proporcionar informações adicionais sobre a administração dos recursos financeiros.

\section{Referências}

ALVARENGA, R. A. Estudo dos fatores contribuintes para a mortalidade das Micro e Pequenas Empresas do Estado do Maranhão. International Journal of Innovation, v. 4, n. 2, p. 106-118, 2016.

ASSAF NETO, A. Estrutura e Análise de Balanços. 10. ed. São Paulo: Atlas, 2012.

BLANC, S. M.; SETZER, T. Analytical debiasing of corporate cash flow forecasts. European Journal of Operational Research, v. 243, n. 3, p. 1004-1015, 2014.

BRASIL. Lei Geral das Micro e Pequenas Empresas. Lei n 123 de 14 de dezembro de 2006. [S.1: s.n.]. , 2006 
CARDOSO, R. L. et al. Contabilidade Geral: introdução a contabilidade societária e contabilidade gerencial. São Paulo: Atlas, 2011.

CASALI, Maristela da Silva; TRETER, Jaciara. A importância da utilização da gestão financeira em microempresas da cidade de Cruz Alta. 2015.

CAVALCANTI, Karoline Almeida; LOURENÇO, Rosenery Loureiro. Controle e contabilidade em prol do desenvolvimento local: status quo de micro e pequenas empresas pontaporanenses. Anais-Encontro científico de administração, economia e contabilidade, v. 1, n. 1, 2014.

COUTEN, Janio de Jesus. Contabilidade gerencial: ferramenta de gestão para a tomada de decisões de micro e pequenas empresa. Nova Xavantina, 18 ago. 2018.

CPC, C. de P. C.-. CPC 03(R2) - Demonstração de Fluxo de Caixa. . [S.1: s.n.], 2010.

FORMENTI, Michele Caroline Lima; MARTINS, Isabel Cristina Silva. Análise da gestão financeira nas micro e pequenas empresas de Osasco. REMIPE-Revista de Micro e Pequenas Empresas e Empreendedorismo da Fatec Osasco, v. 1, n. 1, p. 40-61, 2015.

GITMAN, L. J. Princípios da Administração Financeira. São Paulo: Harba, 1997.

HENDRIKSEN, E. S.; BREDA, M. F. V. Teoria da Contabilidade. 1 ed 12 re ed. São Paulo: Atlas, 2015.

HENRIQUE, Marco A. A importância da contabilidade gerencial para micro e pequena empresa. Universidade de Taubaté. São Paulo, 2008.

HOJI, M. Administração Financeira e Orçamentária. 11. ed. São Paulo: Atlas, 2014.

LIMA, Leonardo J. Almeida; SOUSA, Lilian Santos. A importância das ferramentas contábeis gerenciais para a continuidade e otimização das atividades das micro e pequenas empresas: uma pesquisa de campo na Feira da Oito de Maio em Icoaraci-Belém (Pa). Amazônia em foco: Ciência e Tecnologia, v. 2, n. 3, p. 117-138, 2013.

LAURENTINO, Anderson José et al. A importância da Contabilidade Gerencial para as micro e pequenas empresas no século XXI no Brasil. Curitiba, 2008.

MATARAZZO, D. C. Análise Financeira de Balanços: abordagem básica e gerencial. 6. ed. ed. São Paulo: Atlas, 2003.

OLYNTHO, César Luís Souto; RIBEIRO, Adervaldo Chaves; MUNHÃO, Eder Eugenio. A contabilidade gerencial nas micro e pequenas empresas do comércio de confecções de cidade de Tangará da Serra-MT. Revista UNEMAT de Contabilidade, v. 2, n. 4, 2013. 
PANDOLFO, M. S. de M.; VELOSO, P. R. Análise da mortalidade das micro e pequenas empresas e evidências para o município de Passo Fundo-RS. Teoria da Evidência Econômica, v. 8, n. 14, p. 77-95, 2000.

PIVETTA, G. A Utilização Do Fluxo De Caixa Nas Empresas: Um Modelo Para a Pequena Empresa. Revista Eletrônica de Contabilidade (Descontinuada), v. 1, n. 2, p. 14, 2004.

ROSA, P. M. da; SILVA, A. T. da. Fluxo de caixa - instrumento de planejamento e controle financeiro e base de apoio ao processo decisório. Revista Brasileira de Contabilidade, v. 135, p. 82-95, 2002.

ROSS, S. A.; WASTERFIELD, R. W.; JORDAN, B. D. Princípios de Administração Financeira. São Paulo: Atlas, 1998.

SÁ, C. A. Fluxo de Caixa: a visão da tesouraria e da controladoria. 2. ed. São paulo: Atlas, 2008.

SÁ, C. A. Orçamento Empresarial: Novas Técnicas de Elaboração e de Acompanhamento. São Paulo: Atlas, 2014.

SEBRAE. Sobrevivência das Empresas No Brasil. . Brasília: [s.n.], 2016.

STROBEL, C. D. The Importance of Cash Flow Planning for Closely Held Businesses. The Journal of Corporate Accounting \& Finance, v. 27, n. 1, p. 41-44, 2014.

SUNDER, S. Teoria da Contabilidade e do Controle. São Paulo: Atlas, 2014.

TOLEDO FILHO, J. R. de; OLIVEIRA, E. L. de; SPESSATTO, G. Fluxo De Caixa Como Instrumento De Controle Gerencial Para Tomada De Decisão : Um Estudo Realizado em Microempresas. Revista de Contabilidade do Mestrado em Ciências Contábeis da UERJ, v. 15, n. 2, p. 75-88, 2010. 